\title{
Contrasting Conditions in the U.K. Winter of 2015/16 as a Result of Remote Tropical Influences
}

\author{
Anna Maidens, Jeff Knight, Nicola Martin, And Martin Andrews \\ Met Office, Exeter, United Kingdom
}

(Manuscript received 3 July 2018, in final form 25 February 2019)

\begin{abstract}
Winter 2015/16 exhibited contrasting weather patterns in western Europe. Early winter saw a succession of high-impact storms, and December was the wettest calendar month recorded in the United Kingdom. February experienced a shift to relatively cooler conditions. Overall, the winter was well forecast by GloSea5, the Met Office's seasonal prediction system, capturing the positive North Atlantic Oscillation (NAO) in early winter and the northwesterly pattern of flow in February. In this paper, we use a series of atmospheric relaxation experiments to investigate tropical drivers of these signals and the shift in pressure patterns over the course of the winter. While December's positive NAO is highly consistent with the strong El Niño event in the tropical Pacific Ocean, this pattern is shown to be modified by wavelike activity from the tropical Atlantic Ocean. The result is a shift in the direction of the prevailing flow from westerly to southwesterly, helping to explain the unusually high U.K. precipitation. In February, the surface pressure pattern is characteristic of a strong (rather than a moderate) El Niño, driven by the eastward extension of the Walker circulation. The relaxation experiments indicate that both the Pacific and Atlantic basins play a role in explaining the phenomena of winter 2015/16. To correctly predict the extratropical response over northern Europe, an accurate representation of tropical forcings in both basins is required.
\end{abstract}

\section{Introduction}

December 2015 was the wettest calendar month on record (from 1910) in the United Kingdom, with $182 \%$ of long-term average rainfall. The winter as a whole (from December 2015 to February 2016) was the second-wettest on record and the wettest recorded in Scotland and Northern Ireland (Kendon et al. 2016). The extremely wet and windy conditions were associated with a succession of high-impact storms that caused extensive flooding in northern England, damage to infrastructure, disruption to transport, and power cuts (Parry et al. 2016).

These extreme conditions came just two years after the very wet winter of 2013/14 (Kendon and McCarthy 2015; Knight et al. 2017), which is the wettest meteorological winter (December-February) in the U.K.average record. It also occurred against the backdrop of a highly disproportionate number of rainfall records for other months and seasons that have been set since 2000 (Knight et al. 2017), thus adding to the

\footnotetext{
Corresponding author: Anna Maidens, anna.maidens@ metoffice.gov.uk
}

suggestion that anthropogenic climate change is becoming increasingly manifest in extreme U.K. weather conditions. While attribution of U.K. winter rainfall has shown that anthropogenic influences substantially increase the chances of extreme rainfall totals (e.g., Pall et al. 2011; Coumou and Rahmstorf 2012), the thermodynamic contribution to rainfall changes (via increased moisture availability in a warmer atmosphere) only accounts for a small fraction of the observed rainfall surplus in these winters (Knight et al. 2017). The apparent trends in U.K. rainfall clearly contain a substantial contribution from an increased frequency of atmospheric circulation patterns that favor above-average U.K. rainfall (Ummenhofer et al. 2017). It is not clear whether the change in circulation is the result of climate change, however, given the range of climate change projections of circulation (Christidis and Stott 2015; Fereday et al. 2008). Alternatively, the modest thermodynamic rainfall trend may be being complemented by substantial yearto-year and decadal variability. These uncertainties make it important to understand the origins of extreme monthly rainfall totals such as that for December 2015. 
The North Atlantic Oscillation (NAO) is one of the main factors determining winter weather over the United Kingdom and northern Europe (Hurrell 1995; Smith et al. 2014), with changes in the NAO playing a role in changes in frequencies of extreme events (Scaife et al. 2008). It results from the day-to-day variability of synoptic eddies and the eddy-driven midlatitude jet, moderated by slowly varying drivers of its average behavior (Thompson et al. 2003; Luo 2007). The Met Office Global Seasonal Forecast System, version 5 (GloSea5; MacLachlan et al. 2015), provides skillful forecasts of the NAO (Scaife et al. 2014a), and operational forecasts issued in November 2015 gave useful real-time forecasts of the anomalous atmospheric circulation patterns (Scaife et al. 2017a). Likely drivers of the successful prediction included the near-record El Niño in the Tropical Pacific Ocean, along with the westerly phase of the quasi-biennial oscillation (QBO), both of which are associated with an increased likelihood of a positive phase of the NAO in early winter (Huang et al. 1998; Marshall and Scaife 2009; Ayarzagüena et al. 2018). A westerly phase of the QBO is associated with lower-than-average pressure over the Arctic and higher-than-average pressure over midlatitudes (Boer and Hamilton 2008; Fereday et al. 2012), giving a positive NAO in the Atlantic Ocean sector. El Niño also affects conditions in late winter, with moderate events giving rise to negative NAO conditions (Baldwin and Dunkerton 2001; Ineson and Scaife 2009; Ayarzagüena et al. 2018), whereas strong events give rise to a central Atlantic ridge and cyclonic pattern over Scandinavia (Toniazzo and Scaife 2006; Brönnimann 2007). The model underlying GloSea5 gives good ENSO behavior and teleconnections (MacLachlan et al. 2015). While the QBO link is generally less robust in models, representation of both mechanisms within the GloSea5 system contributes to its forecast skill (Scaife et al. 2014b). It has been suggested that the ENSO teleconnection to the NAO can be modulated by influences from the tropical Indian Ocean (Hoerling et al. 2001). Yeh et al. 2018 suggest that the biggest impact follows a combination of negative Indian Ocean dipole (IOD) in the preceding autumn and winter El Niño. In autumn 2015 , however, there was a positive IOD state which is considered to have a lower impact on the ENSO teleconnection to the Atlantic and Europe.

For December, the GloSea5 system (supplemented by information from other seasonal prediction systems) allowed the issue in November of an outlook for the United Kingdom warning of "an increased risk of above-average rainfall" and the "risk of spells of windy or even stormy weather." At a detailed level, however, examination of the European Centre for Medium-Range
Weather Forecasts interim analysis, or ERA-Interim (hereinafter ERAI; Dee et al. 2011), mean sea level pressure (MSLP) field shows that the positive NAO was present but modified somewhat by a trough over the central-eastern North Atlantic Ocean, leading to a southwesterly mean flow over the United Kingdom in December rather than the westerly flow suggested by the positive NAO in the forecast. This is likely to have contributed to the extremely wet conditions, due to the flow over the United Kingdom having a more southerly origin than usual over warmer subtropical oceans (a factor that has been identified in past flooding events in the United Kingdom; Lavers et al. 2011). Support for this hypothesis comes from a region of enhanced rainfall along this southwesterly track, which can be seen in the Global Precipitation Project Climatology (GPCP; Pendergrass et al. 2016) precipitation anomalies (see Fig. 1).

While the positive NAO is likely to have been a result of the global drivers mentioned above, the causes (i.e., factors other than unpredictable weather noise) of the southerly deviation of the jet stream warrant investigation. A similar feature was seen in the winter of 2013/14, and was attributed to a remote influence from anomalous rainfall over the Amazonian region (Knight et al. 2017), so one hypothesis is that an influence of anomalous rainfall in the tropics (via atmospheric Rossby waves; Scaife et al. 2017b), especially the tropical Atlantic, may have modified the midlatitude pressure patterns. The particular importance of wave sources in the tropical Atlantic for pressure patterns in the North Atlantic sector arises because waves with low wavenumbers (able to reach midlatitudes without reflection or absorption) have group velocities that are directed more northward than eastward. Tropical rainfall anomalies and the resulting Rossby waves are well represented in GloSea5 and are thus another factor to consider in analyzing the forecast for 2015/16.

January 2016 was a mixture of some very wet spells and a much colder and drier spell during the middle of the month, and was largely dominated by synoptic timescale variability. As a transitional month dominated by weather noise, it is not included in this study. In contrast, February 2016 was more consistent in being cooler and drier than the early winter, with U.K.-average temperatures and rainfall often close to or below the climatological average (Kendon et al. 2017). This arose from a dipole MSLP pattern with higher-than-usual MSLP over the North Atlantic Ocean and lower-than-usual MSLP over Scandinavia, resulting in a greater occurrence of northwesterly winds. This dipole pattern was typical of the late winter response to a strong El Niño, and was well represented by GloSea5, as can be seen from a 

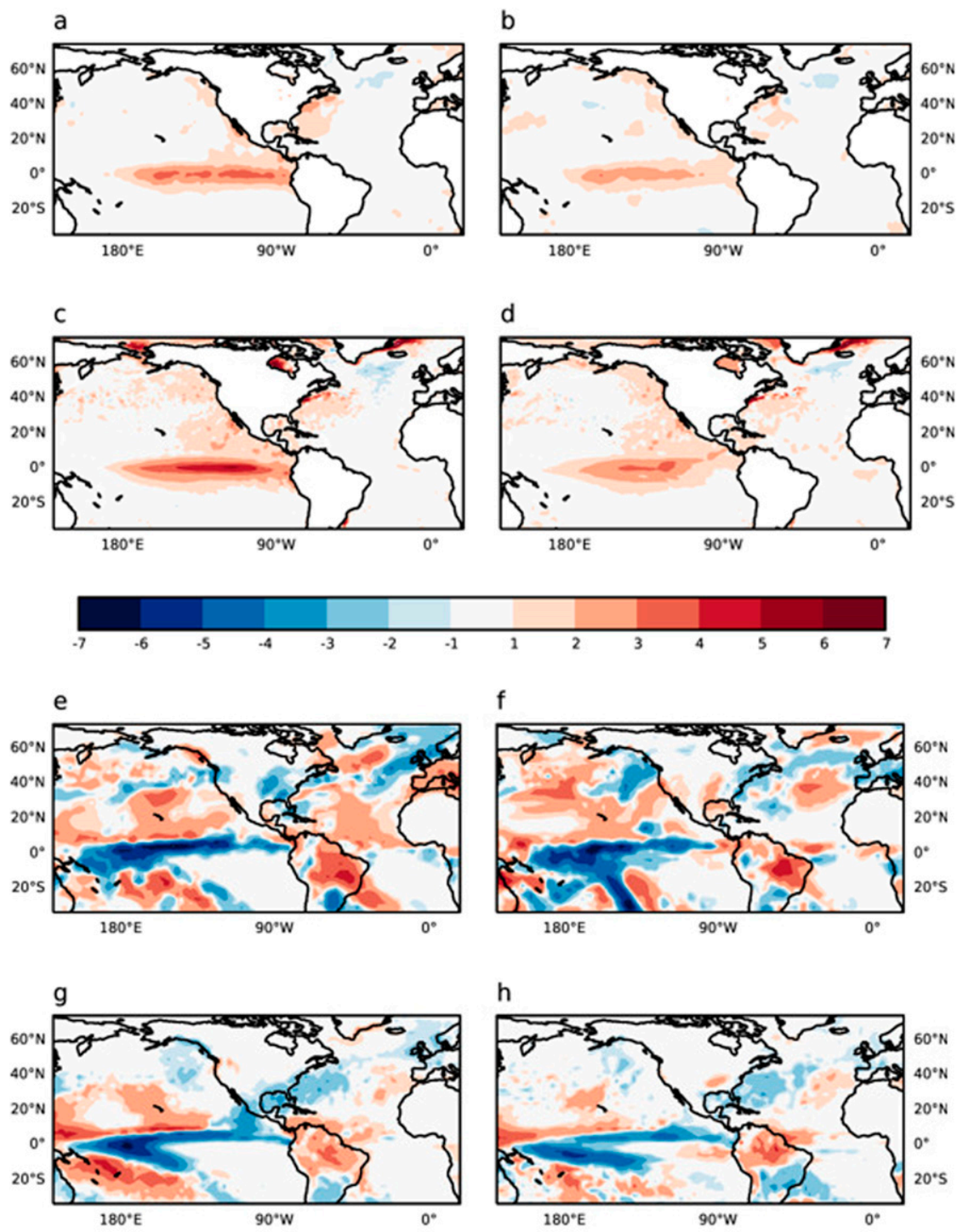

$\mathrm{h}$
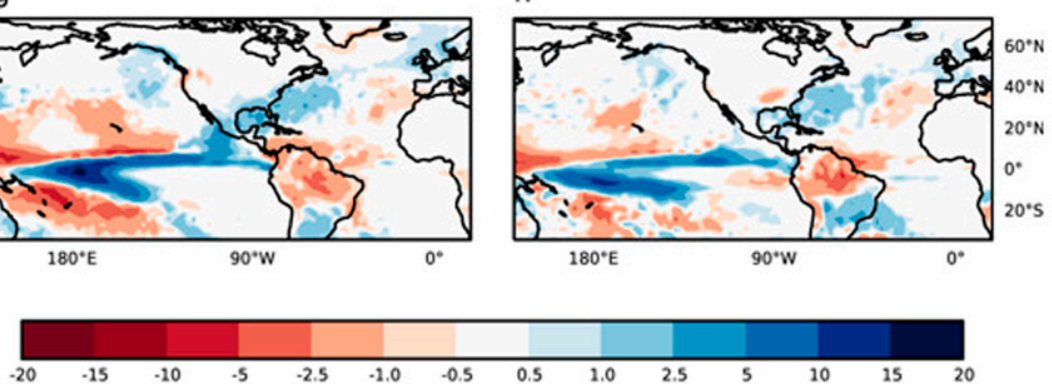

FIG. 1. Observed and forecast tropical conditions in winter 2015/16: Sea surface temperature anomalies $\left({ }^{\circ} \mathrm{C}\right.$ ) for HadISST for (a) December 2015 and (b) February 2016 and (c),(d) the equivalent fields for the ensemble mean of the November 2015 GloSea5 forecast. Precipitation anomalies $\left(\mathrm{mm} \mathrm{day}^{-1}\right)$ from GPCP for (e) December 2015 and (f) February 2016 and (g),(h) the equivalent fields for GloSea5. Observed anomalies are with reference to a climatology period of 1981-2010, and the GloSea5 anomalies are relative to the climatology of its hindcast over 1996-2009 (the climatology period does not affect the pattern of the anomalies or their magnitude in any significant way).

comparison of the reanalysis and forecast fields (albeit with weaker anomalies in the forecast fields; Eade et al. 2014). Analysis of the $60^{\circ} \mathrm{N}, 10 \mathrm{hPa}$ winds in reanalysis (Scaife et al. 2017a) shows that the polar vortex weakened in January and February but did not become easterly until early March (although even the weakening of the westerly vortex may have had some influence;
Birner and Albers 2017). March as a whole was cooler than the long-term climatological average; March, however, lies outside the scope of this paper.

This work addresses three questions. First, can we identify any remote influences which account for the Eastern North Atlantic trough observed in December 2015? Second, does the lack of this very specific feature 
in the GloSea5 prediction point to any deficiency in the simulation of other parts of the globe which have a remote influence on the North Atlantic sector? Third, can we confirm the origin of the shift to the conditions observed in late winter that were successfully predicted by GloSea5? To answer these questions, we explore the possible remote teleconnections using sets of coupled climate model relaxation experiments in which certain regions in the model are relaxed toward observed conditions while the rest of the model is allowed to run freely. In common with many previous studies (Greatbatch et al. 2012, 2015; Gollan et al. 2015; Watson et al. 2016), we focus on the global tropics as a potential source of remote influences on the extratropical North Atlantic. This follows clear examples of strong extratropical responses to persistent tropical disturbances such as in El Niño and La Niña events, which provide a good illustration of the mechanisms by which the atmosphere can provide rapid communication of signals from the deep tropics to middle and high latitudes (Stan et al. 2017).

The paper is laid out as follows. In section 2 we describe the observed state of the tropics in winter 2015/16, and the performance of the real-time GloSea5 forecast. The design of the relaxation experiments is described in section 3. Section 4 gives results from three experiments: all tropics, tropical Pacific, and tropical Atlantic. In section 5 we analyze the dynamical drivers in the reanalysis fields and compare these with those from GloSea5 and the three relaxation experiments. Last, we make our concluding remarks.

\section{Observations and forecasts of winter $\mathbf{2 0 1 5 / 1 6}$}

As noted above, three of the most important sources of tropical influence on the North Atlantic are ENSO, the QBO, and tropical precipitation anomalies. Winter 2015/16 had one of the strongest El Niño events on record (Fig. 1; observed anomalies relative to the HadISST dataset; Rayner et al. 2003) and a strong westerly phase of the quasi-biennial oscillation (QBO), both of which could be expected to contribute to a positive NAO in early winter. Figure 1 also shows GPCP (Pendergrass et al. 2016) rainfall anomalies for December 2015 and February 2016. In December much of the tropical Atlantic north of the Equator and the north coast of South America (barring Venezuela) was drier than average, with a small area of wetter than average conditions over Florida and the Bahamas. In February, the Gulf of Mexico was drier than average, with an anomalously high area of precipitation further east in the tropical Atlantic. The rest of the tropical Atlantic showed average rainfall, with the exception of a small region on the equator suggestive of a southward shift in the intertropical convergence zone (ITCZ).

The extratropical response in the North Atlantic was in line with what would be expected from the tropical conditions in 2015/16. The top row of Fig. 2 shows ERAI MSLP anomalies for December (Fig. 2a) and February (Fig. 2b). The reanalysis field for December projects strongly onto the positive phase of the NAO albeit modified by a southward deviation in the middle to eastern North Atlantic, producing a southwesterly flow. In February, there was anomalously high mid-Atlantic MSLP and anomalously low MSLP over Scandinavia, as would be expected from a strong El Niño event (Huang et al. 1998; Toniazzo and Scaife 2006).

GloSea5, as noted above, produced good forecasts of the season overall and subseasonal details within it. Overall, the forecast system shows high skill for the NAO (MacLachlan et al. 2015). The system uses the coupled HadGEM3 (the expansions of most model acronyms may be found at https://www.ametsoc.org/ PubsAcronymList) model (Hewitt et al. 2011), consisting of the Unified Model atmosphere component (Walters et al. 2011; Brown et al. 2012) with approximately $50-\mathrm{km}$ resolution in midlatitudes and 85 levels in the vertical direction, the NEMO ocean model (Madec 2016) at $0.25^{\circ}$ and 75 vertical levels, the JULES land surface model (Best et al. 2011) and the Los Alamos sea ice (CICE) model (Hunke and Lipscomb 2010). As an operational system, it runs an ensemble of real-time forecasts (produced around the 20th of each month for the following 5-month period) together with hindcasts (historical reforecasts for the period 1996-2009) used for skill assessment and to provide a model climatology against which anomaly fields can be calculated. Forecasts are initialized from operational NWP analyses and analyses from the Met Office's FOAM system; hindcasts from ERAI and the GloSea5 Ocean and Sea Ice Analysis reanalysis. Both the forecast and ocean analyses are constructed using NEMO-VAR (Mogensen et al. 2012). It has a well-resolved stratosphere, so teleconnections with Europe that involve the stratosphere (such as moderate ENSO events) and the influence of other stratospheric variability are well represented. It also has very high correlation skill for Niño-3.4 sea surface temperatures (MacLachlan et al. 2015) at seasonal range. Additionally, the system has skill in predicting tropical rainfall in key regions known to affect the extratropics, and good representation of the resulting teleconnections (Scaife et al. 2017b). These features play a significant part in the high forecast skill for the NAO (anomaly correlation skill of 0.62 ; Scaife et al. 2014a).

Figures $1 \mathrm{c}$ and $1 \mathrm{~d}$ show the forecast sea surface temperature (SST) anomalies for December 2015 and 
(a)

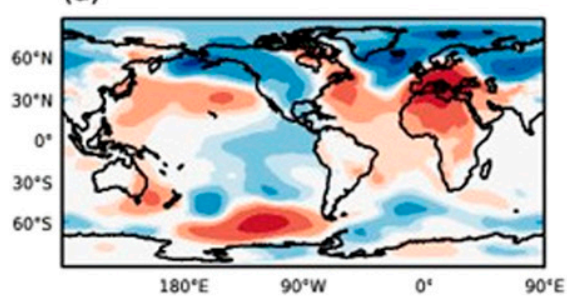

(c)

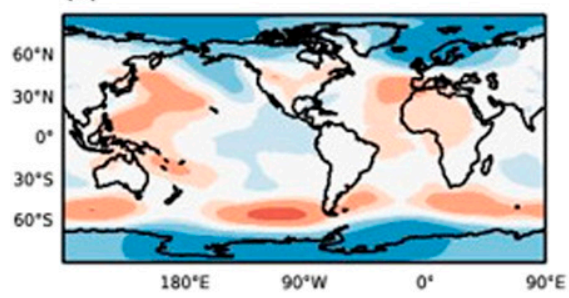

(e)

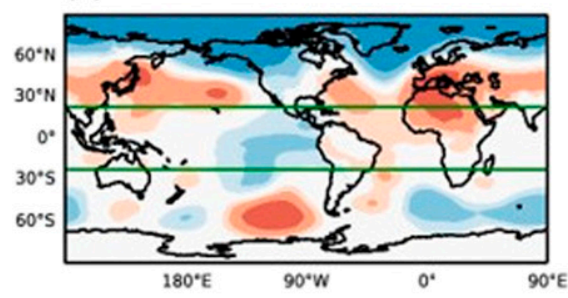

(g)

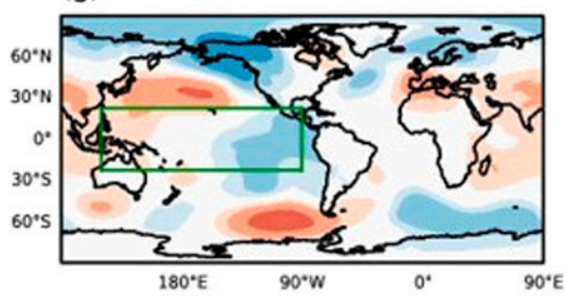

(i)

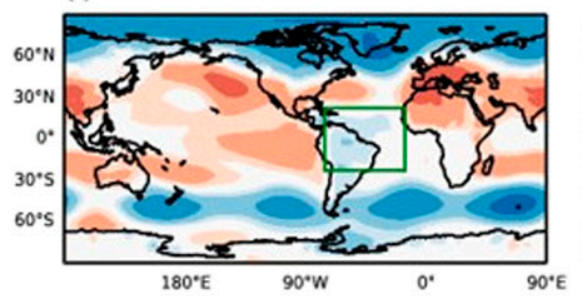

(b)

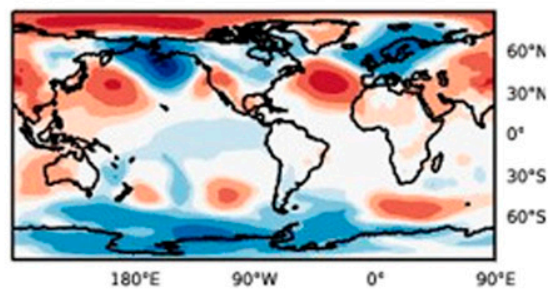

(d)

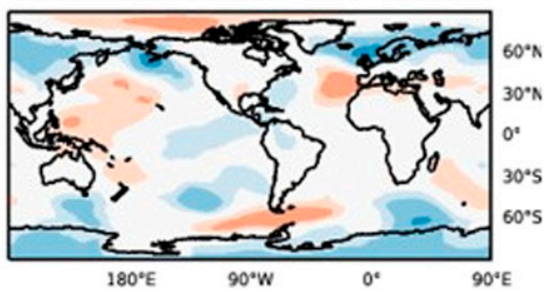

(f)

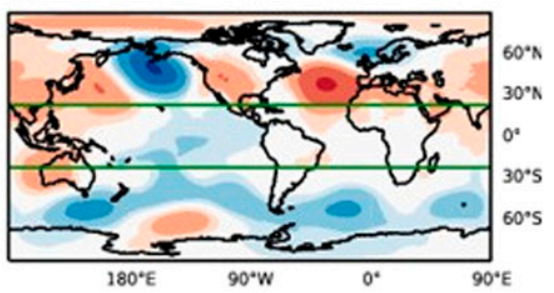

(h)

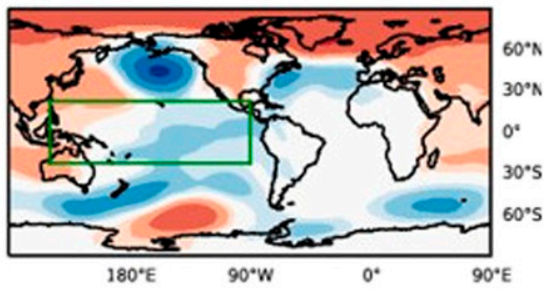

(j)

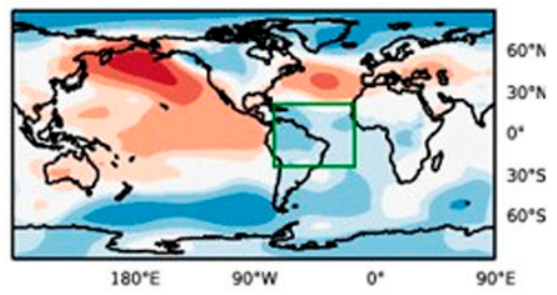

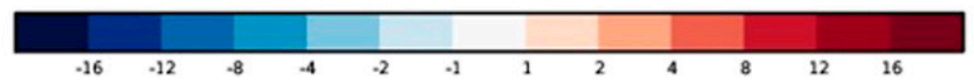

FIG. 2. Winter 2015/16 surface pressure responses in the reanalysis and various numerical experiments: MSLP anomalies (hPa) for (left) December and (right) February. Shown are (a),(b) ERAI (vs 1981-2010 climatology), (c),(d) GloSea5 real-time seasonal forecast anomalies (relative to 1996-2010 climatology; initialized 1 Nov), and relaxation experiments for the (e),(f) all-tropics domain, (g),(h) tropical Pacific domain, and (i),(j) tropical Atlantic domain. 
February 2016 produced using forecast ensembles initialized in early November 2015. The GloSea5 forecast correctly reproduced the exceptionally strong El Niño, if anything slightly overestimating the strength of the anomalies. February's forecast was also accurate in terms of the overall pattern and amplitude of ENSO. Figures $1 \mathrm{~g}$ and $1 \mathrm{~h}$ show the forecast precipitation anomalies. Overall, the large-scale patterns of tropical precipitation anomalies are well reproduced. One notable difference between the forecast and observations, however, is that the enhanced rainfall over the Caribbean stretches from Central America to Florida in the forecast field for December, whereas in the GPCP dataset the rainfall is more tightly confined to the region around Florida and Cuba. Note also that the forecast ensemble mean showed a signal for heavy rainfall over southern California in December, whereas in fact rains normally associated with El Niño did not occur. This may have been due to the westerly shift in maximum position of the warm pool, affecting teleconnections with California (Jong et al. 2018). The forecast system therefore had in place several of the potential tropical drivers for the extratropical response over the North Atlantic and Europe, since anomalous rainfall is diagnostic of convective disturbances that can create teleconnections to the extratropics via Rossby waves.

The GloSea5 forecasts shown in Figs. $2 \mathrm{c}$ and $2 \mathrm{~d}$ are the ensemble mean anomalies from forecasts initialized around first November 2015. For December 2015, GloSea5 correctly forecast a positive NAO. The flow over the United Kingdom was forecast to favor westerly winds, and gave guidance on the enhanced likelihood of stormy conditions and heavy rainfall. For February, the forecast system also captured the mid-Atlantic high MSLP anomaly and Scandinavian low MSLP anomaly pattern, providing an indication of a likely shift to colder conditions as a result of an anomalous mean northwesterly flow toward the end of the winter. The amplitude of the signal in the forecasts was smaller than in reanalysis, as is typical for winter seasonal forecasts. This feature of seasonal predictions is referred to as the signal-to-noise paradox (Eade et al. 2014).

Table 1 shows the pattern correlations between GloSea5 and the reanalysis fields. Correlations are calculated for the whole of the extratropics, North Atlantic and North Pacific. For the North Atlantic, pattern correlations are high: 0.66 and 0.70 respectively for December and February. To quantify what counts as a significant pattern correlation, we used a Monte Carlo simulation of randomly paired reanalysis years taken from 36 years of ERAI (excluding identical years) to calculate pattern correlations. The results varied by region chosen for the comparison: for the whole of the extratropics, correlations
TABLE 1. Pattern correlation coefficients for MSLP fields between ERAI and GloSea5 and between ERAI and the three relaxation experiments. The regions compared are all extratropics $\left(22.5^{\circ}-80^{\circ} \mathrm{N}\right)$, North Atlantic $\left(22.5^{\circ}-80^{\circ} \mathrm{N}, 15^{\circ}-75^{\circ} \mathrm{W}\right)$, and North Pacific $\left(22.5^{\circ}-80^{\circ} \mathrm{N}, 120^{\circ}-270^{\circ} \mathrm{E}\right)$. Statistically significant pattern correlations are shown in boldface type.

\begin{tabular}{lccc}
\hline \multicolumn{1}{c}{ Expt } & Extratropics & North Atlantic & North Pacific \\
\hline \multicolumn{4}{c}{ December } \\
GloSea5 & $\mathbf{0 . 5 5}$ & $\mathbf{0 . 6 7}$ & 0.44 \\
All tropics & $\mathbf{0 . 7 3}$ & $\mathbf{0 . 9 1}$ & $\mathbf{0 . 7 0}$ \\
Tropical Atlantic & $\mathbf{0 . 5 7}$ & $\mathbf{0 . 7 3}$ & 0.29 \\
Tropical Pacific & $\mathbf{0 . 5 7}$ & 0.27 & $\mathbf{0 . 7 9}$ \\
\multicolumn{4}{c}{ February } \\
GloSea5 & $\mathbf{0 . 6 0}$ & $\mathbf{0 . 7 0}$ & $\mathbf{0 . 7 7}$ \\
All tropics & $\mathbf{0 . 8 1}$ & $\mathbf{0 . 9 3}$ & $\mathbf{0 . 8 4}$ \\
Tropical Atlantic & -0.15 & 0.64 & -0.46 \\
Tropical Pacific & 0.22 & -0.53 & $\mathbf{0 . 7 0}$ \\
\hline
\end{tabular}

in excess of 0.4 were unlikely ( $90 \%$ level) to occur by chance; for the North Pacific the threshold was 0.5; whereas for the North Atlantic the threshold was 0.65.

In December, the patterns are broadly similar, with a positive NAO, but differ in detail (in particular the southward deviation in the low pressure anomaly). In February the agreement is remarkably good. For the North Pacific, the pattern correlation is very high in February (0.77), but it is lower in December the correlation is lower (0.44), probably because the high pressure extending to the east of the Hawaiian islands in reanalysis was not predicted in the December GloSea5 ensemble mean. This could be a failure of the prediction, or could also arise from unpredictable internal variability not represented in the ensemble mean. Additionally, the domain over which the pattern correlations are calculated overlaps the margins of adjacent continental areas where there is also less agreement between the ensemble mean and reanalysis.

In summary the forecast ensemble mean correctly captured many observed features, specifically the positive NAO in early winter and the mid-Atlantic high/ Scandinavian low in February. There were, however, some details in the reanalysis fields which were not present in the forecast ensemble mean, such as the southwesterly flow over the United Kingdom in December. We now turn to relaxation experiments to investigate the origins of these features and assess whether any of them were in principle predictable, indicating missing mechanisms in the forecast model, or whether they arose from unpredictable noise.

\section{Experimental design}

To investigate the impact of tropical drivers on the extratropical circulation, we performed sets of seasonal-length 
coupled ocean-atmosphere model simulations with the inclusion of relaxation, using the Met Office coupled ocean-atmosphere model, HadGEM3 (Hewitt et al. 2011). The experiments used an atmospheric resolution of approximately $50 \mathrm{~km}$ in the midlatitudes and $90 \mathrm{~km}$ at the equator, 85 levels in the vertical direction with a wellresolved stratosphere and a model top of $85 \mathrm{~km}$, and ocean resolution of $0.25^{\circ}$ with 75 vertical levels, in line with the model settings in the GloSea5 system. The model was relaxed toward ERAI fields over specified regions, while the rest of the model was allowed to evolve freely. Model fields were relaxed at each time step of the simulation by adding a fraction of the difference between the model field and reanalysis field at that time step (the fraction chosen determining the effective relaxation time scale). A detailed description of the relaxation technique can be found in Knight et al. (2017). Similar techniques have been used extensively in both case studies (Greatbatch et al. 2015) and investigating climate variability (Gollan et al. 2015).

We relaxed the simulated temperature $T$ and the horizontal components of wind $u$ and $v$ toward analyzed values with an $e$-folding time scale of $6 \mathrm{~h}$. Three experiments were performed: an all-tropics experiment $\left(22.5^{\circ} \mathrm{S}-22.5^{\circ} \mathrm{N}\right)$, as well as tropical Atlantic $\left(22.5^{\circ} \mathrm{S}-\right.$ $\left.22.5^{\circ} \mathrm{N}, 15^{\circ}-75^{\circ} \mathrm{E}\right)$ and tropical Pacific $\left(22.5^{\circ} \mathrm{S}-22.5^{\circ} \mathrm{N}\right.$, $120^{\circ} \mathrm{E}-90^{\circ} \mathrm{W}$ ) experiments. In each, relaxation was performed throughout the depth of the troposphere and into the lower stratosphere up to a height of approximately $20 \mathrm{~km}$. The regions can be seen in Fig. 2. The relaxation time scale was tapered to zero over $12.5^{\circ}$ of longitude at the lateral boundaries to minimize any shock to the zonal trade winds at the edges of the domains. The instantaneous 6-hourly ERAI fields were linearly interpolated to the model grid to obtain a relaxation "target" field at each time step of the model dynamics.

For each of the three experiments, we produced two hindcast sets of 70 members, five for each of the years 1996-2009 (in line with the operational hindcast). Each member was initialized with ocean and atmosphere reanalyses for November first of that year, consisting of ERAI for the atmosphere component and the GloSea5 Ocean and Sea Ice Analysis, as detailed above. The hindcast period 1996-2009 was chosen to match that used in the operational forecasts produced for winter 2015/16. In one set, the region under investigation (all tropics, tropical Atlantic, or tropical Pacific) was relaxed toward reanalysis for the winter of 2015/16 (regardless of date of initialization). In the other set of hindcasts, the region was relaxed toward reanalysis for the winter corresponding to the year of initialization. For each of the three relaxation experiments, anomalies were calculated by taking the difference between the hindcast set relaxed to 2015/16 and the hindcast set where each initialization year was relaxed to reanalysis for the corresponding winter. This enabled the anomalous effects of tropical conditions in winter 2015/16 to be computed removing any systematic effect of the relaxation technique itself. Because of the use of a set of initialization years, it is only within the relaxation domain that the ensemble mean signal relates to winter 2015/16 (through the reanalysis information supplied in the relaxation domain), since the influence of the initial conditions cancels out to first order outside this region.

\section{Results of relaxation experiments}

\section{a. Surface responses in December 2015}

The left-hand column of Fig. 2 shows MSLP anomalies for December 2015. Figures 2a and 2c (ERAI and GloSea5 forecast, respectively) have been discussed above. Our focus is on the trough in the North Atlantic, which is important because it brought southwesterly flow across the United Kingdom, and the change in the extent of the low and high pressure bands in the North Pacific.

Figures $2 \mathrm{e}, 2 \mathrm{~g}$, and $2 \mathrm{i}$ show the results of the relaxation. The all-tropics experiment improves both the features noted above, and increases the pattern correlation over the North Atlantic to 0.91 (Table 1). The signal over the North Pacific is also broadly correct (correlation of 0.70 ), although the center of the low pressure is moved slightly east of the Aleutian Islands, toward Alaska. The details over land are largely reproduced with minor differences over North America; the low pressure anomalies in reanalysis stretching from Alaska to the coast of the Gulf of Mexico are confined to Alaska and the Great Plains in the all-tropics experiment.

The tropical Atlantic and tropical Pacific experiments both perform well in the ocean basin in which relaxation is applied (correlations above 0.70 ) but do not give a good reproduction of reanalysis features in the extratropics in the other ocean basin. The tropical Pacific experiment gives part of the positive NAO signal over western Europe, but the anomaly is weaker than in the all-tropics experiment. Note that, in both the all-tropics and tropical Pacific experiments, the only information about the unusually strong El Niño in winter 2015/16 comes from the atmospheric relaxation, since the wide range of hindcast years removes any effect from SSTs. As a result, any effect from El Niño that relies on a teleconnection via the tropical Atlantic will only be present if connections within the tropics are well represented. 
In contrast to the tropical Pacific simulations, the tropical Atlantic simulations (Fig. 2i) reproduces the reanalysis MSLP pattern in the North Atlantic much better, including a representation of the trough feature seen in the reanalysis. This suggests that the observed North Atlantic MSLP pattern has a significant part of its origins in the tropical Atlantic (specifically tropical wave trains originating in the Gulf of Mexico; Ayarzagüena et al. 2018). Unsurprisingly, the pattern in the Pacific is not well represented (correlation of only 0.29 ). This is expected as the experiments are initialized ENSOneutral on average, and the tropical Pacific atmosphere does not receive information about the El Niño through relaxation as it does in the other relaxation experiments.

\section{b. Surface responses in February 2016}

The right-hand column of Fig. 2 shows MSLP patterns for February 2016. The ERAI (Fig. 2b) shows a pattern with a deepened Aleutian low in the Pacific characteristic of an El Niño event. In addition, there is anomalously high MSLP in the mid-North Atlantic and anomalously low MSLP over Scandinavia, which is characteristic of a strong El Niño event (Toniazzo and Scaife 2006). The pattern of response over the North Atlantic is reproduced to a large extent (correlation of 0.70 ) by the GloSea5 forecast (Fig. 2d), although again, the amplitude is considerably smaller.

As for December, relaxing the whole of the tropics (Fig. 2f) gives a good reproduction of the observed Northern Hemisphere extratropical response (correlation of 0.93). The tropical Pacific experiment (Fig. 2h) gives a good representation of the North Pacific (correlation of 0.64 ) but incorrectly gives a negative NAO in the North Atlantic sector (correlation of -0.53). Note, however, that negative NAO is the canonical response to moderate El Niño events. In contrast, the tropical Atlantic experiment (Fig. $2 \mathrm{j}$ ) produces results with a greater degree of similarity to reanalysis in the North Atlantic (pattern correlation of 0.63 ), albeit with the low pressure anomalies shifted northwest from Scandinavia toward Iceland. The simulation in this case is less faithful than in the all-tropics relaxation case, as can be seen from the lower pattern correlation.

The differing responses are due to the various physical mechanisms in play: tropospheric responses involving wave patterns from the tropical Pacific (Horel and Wallace 1981) resulting in the intensification of the Pacific-North America (PNA) pattern, and from the tropical Atlantic (Brönnimann et al. 2007); and stratospheric mechanisms resulting from perturbations to the Aleutian low resulting in upward propagating stationary waves and wave breaking in the stratosphere (Toniazzo and Scaife 2006). For moderate El Niño events, stratospheric wave-breaking modulates the likelihood of sudden stratospheric warmings (SSWs; Ineson and Scaife 2009) and thereby the chances of negative NAO and cold easterly winds (Baldwin and Dunkerton 2001). However, when tropospheric influences from the tropical North Atlantic come to dominate in strong El Niño events, rather than a negative NAO, we see a central Atlantic ridge and a cyclonic pattern over Scandinavia (Toniazzo and Scaife 2006; Brönnimann 2007).

In summary, it appears that in February, while the tropical Atlantic sector influenced the MSLP patterns over the North Atlantic to the greatest extent, other regions of the tropics may have modulated the Atlantic response to some degree.

\section{c. Responses in the upper troposphere}

We now turn to the upper-troposphere patterns in the experiments to examine more closely the connections between the tropical and Northern Hemisphere atmosphere evident in the MSLP fields. Our hypothesis is that these connections are established through the propagation of Rossby waves from the tropics to the extratropics, as has been seen in many other contexts (Sardeshmukh and Hoskins 1988; Scaife et al. 2017a; Knight et al. 2017). The upper-tropospheric azonal streamfunction anomaly enables a clearer picture of quasi-stationary planetary wave patterns.

Figure 3 shows the 200-hPa azonal streamfunction anomalies for December (left-hand column) and February (right-hand column). The reanalysis fields (Figs. $3 a, b)$ show wavelike patterns emanating from the tropical oceans. In the Pacific, for December this wave pattern appears to give an east/west dipole of negative/ positive streamfunction anomalies over northern North America, reminiscent of a PNA wave pattern. In February, the wavelike activity shows a deepened Aleutian low, positive anomalies over western North America, and negative anomalies over the southeastern North America. Wavelike patterns are also evident in the North Atlantic. In December there is a pattern appearing to originate in the Caribbean with positive anomalies over eastern North America, negative anomalies to the south of Greenland, and positive anomalies over Europe. In February, in contrast, wavelike activity appears to originate in the central tropical Atlantic, and propagates north east.

The GloSea5 forecast fields (Figs. 3c,d) capture the Pacific patterns reasonably well, although amplitudes become weaker than reanalysis in midlatitudes. In the North Atlantic, the tropical streamfunction anomalies are well predicted (albeit weaker than observed), but the midlatitude patterns are only simulated in February. 
(a)

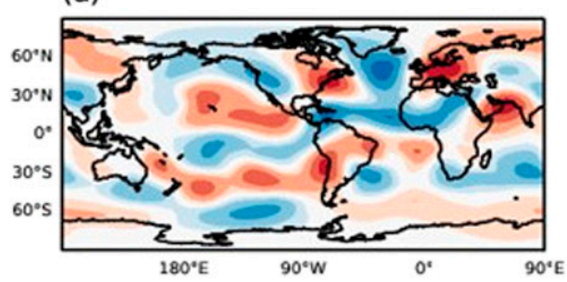

(c)

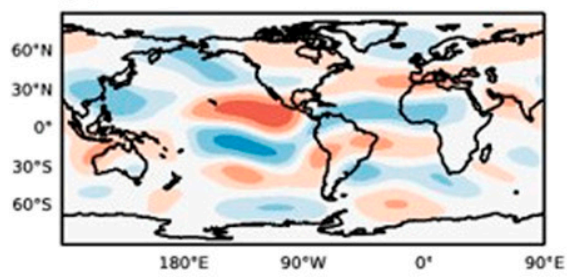

(e)

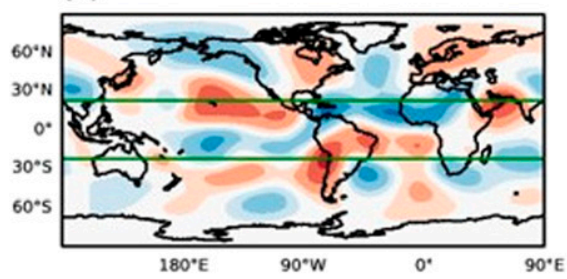

(g)

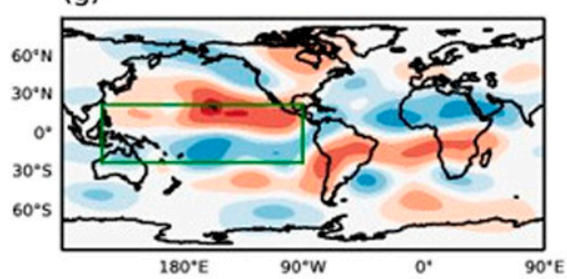

(i)

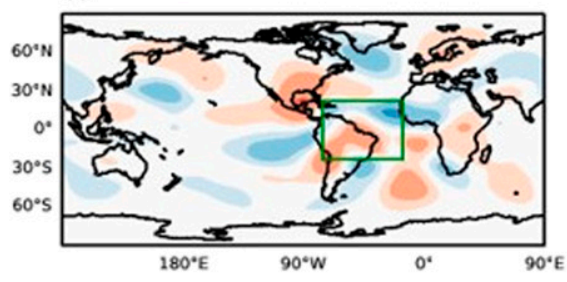

(b)

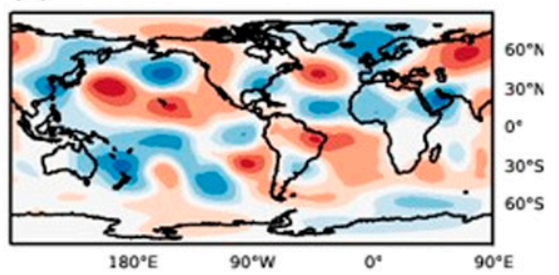

(d)

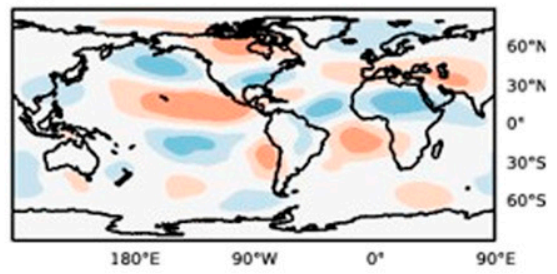

(f)

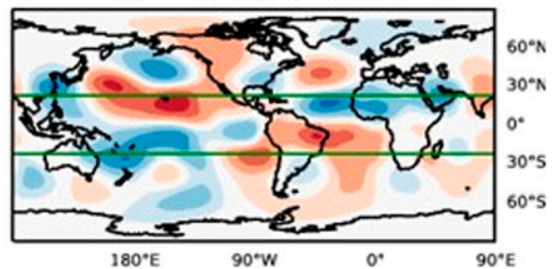

(h)

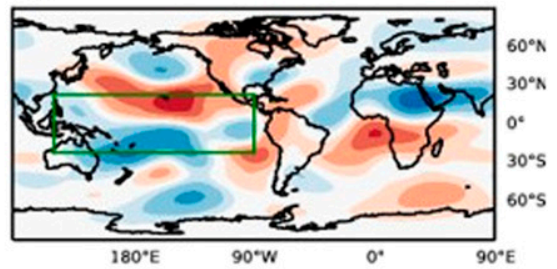

(j)

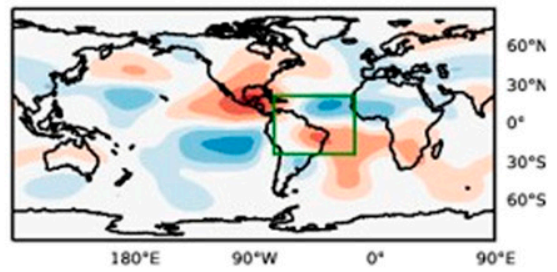

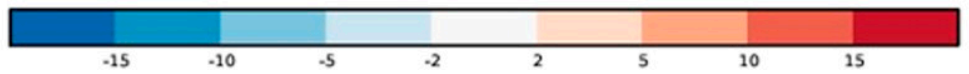

FIG. 3. Upper-tropospheric flow in winter 2015/16: As in Fig. 2, but for azonal streamfunction anomalies at $200 \mathrm{hPa}\left(10^{6} \mathrm{~m}^{2} \mathrm{~s}^{-1}\right)$.

In December, the forecast midlatitude streamfunction anomalies reinforce the local zonal flow by adding to the zonal mean zonal flow. The wavelike pattern of anticyclonic and cyclonic anomalies across the North Atlantic in the reanalysis field is absent however. The surface features shown in Fig. 2 are strongly associated with these upper-tropospheric features as would be expected from Rossby waves which produce equivalent barotropic responses in midlatitudes. The predicted upper-tropospheric pattern in December is consistent, therefore, with the prediction of positive NAO at the surface. However, the forecast field lacks the mid-North Atlantic trough feature, which reanalysis suggests is related to a wavelike pattern in the upper azonal flow.

As at the surface, the all-tropics relaxation experiments show considerable similarities to reanalysis in the 
upper-tropospheric extratropical Northern Hemisphere (Figs. 3e,f). The pattern of alternating anomalies stretching across the North Atlantic and into northern Europe in December is reproduced, with weaker intensity than reanalysis. The tropical Pacific relaxation experiments, however, reproduce observed patterns over the Pacific and North America (Figs. 3g,h), but there are only very weak anomalies across the extratropical North Atlantic. In contrast, the tropical Atlantic experiments (Figs. 3i,j) show comparatively small anomalies in the North Pacific, and the patterns do not resemble reanalysis. However, in December in the Atlantic there is a wavelike pattern which appears to extend from the Caribbean along the eastern coast of North America, with a negative anomaly to the south of Greenland. This pattern is similar to that in the reanalysis and suggests that the tropical Atlantic is at least partly responsible for creating the North Atlantic anomaly that leads to the surface trough feature seen in reanalysis. For February, the tropical Atlantic experiment shows clear similarity to the observed dipole over the North Atlantic and northern Europe, although these features are considerably weaker.

In summary, these results suggest that in both early and late winter there are tropical influences on the North Atlantic region emanating from the tropical Atlantic sector. While we have not specifically diagnosed these patterns as stationary Rossby wave disturbances, such features appear to be a ubiquitous aspect of the atmospheric dynamics in midlatitude winter (see, e.g., Scaife et al. 2017b), and are closely associated with the surface features shown in the MSLP fields. Simulations relaxing the tropical Pacific alone, however, are unable to capture the observed North Atlantic patterns. Nevertheless, the all-tropics simulations tend to produce better agreement than either subregion. This implies that capturing both the tropical Pacific and tropical Atlantic influences within the forecast is crucial to getting a good representation of streamfunction and MSLP anomalies globally. In the case of December, the seasonal prediction fails to produce the apparent Rossby wave influence from the tropical Atlantic. In the next section, we examine more closely the tropical drivers of these waves to more clearly understand the sources of this discrepancy.

\section{Dynamical analysis of atmospheric drivers}

An indication of the dynamical source regions of Rossby waves can be gained by analysis of the Rossby wave source diagnostic (RWS), which is the rate of change of absolute vorticity of an air parcel following the nondivergent part of the flow (Sardeshmukh and
Hoskins 1988; Shimizu and de Albuquerque Cavalcanti 2011). We write the vorticity equation in terms of the rotational part of the flow $\boldsymbol{v}_{\psi}$ and the divergent part of the flow $\boldsymbol{v}_{\chi}$ (derivable from the streamfunction and velocity potential, respectively),

$$
\frac{\partial \zeta}{\partial t}+\boldsymbol{v}_{\psi} \cdot \nabla \zeta=-\zeta D-\boldsymbol{v}_{\boldsymbol{x}} \cdot \nabla \zeta
$$

where $\zeta$ is the absolute vorticity and $D$ is the divergence. The right-hand side of this equation constitutes the Rossby wave source term which is the sum of the vortex stretching term $\zeta D$ and an advection term $\boldsymbol{v}_{\chi} \cdot \nabla \zeta$. The RWS implies that divergence anomalies in the deep tropics, such as from the ITCZ, are less effective in generating Rossby waves than divergence anomalies off the equator which occur where the absolute vorticity and its meridional gradient are stronger. The deep tropics are where the strongest convective variability is found, however, so production of tropically forced Rossby waves relies on tropical anomalies inducing secondary anomalies that are felt off the equator, such as via changes in the local Hadley circulation (e.g., Knight et al. 2017). Anomalous Hadley circulations create anomalies of both divergent outflow in the upper troposphere (which could lead to vorticity advection) and convergence and descent off the equator (which could lead to compression or stretching of vorticity). The efficiency of anomalous tropical convection in creating Rossby waves is therefore a function of the strength of the anomaly and the latitude of the subtropical jet, as this is where total vorticity tends to increase markedly.

Figure $4 \mathrm{a}$ shows the RWS diagnostics at $200 \mathrm{hPa}$ for December from the ERAI. The northern midlatitudes show a complex pattern of RWS anomalies. Analysis of these diagnostics is complicated by the fact that the extratropical nodes of Rossby waves are also associated with RWS anomalies, even if the true source of that wave is in the tropics. To overcome this, we focus on the RWS anomalies closest to the equator as the likely sources, although this clearly involves a degree of judgement. Regions of negative RWS (blue) can be seen in the tropical Pacific between $10^{\circ}$ and $20^{\circ} \mathrm{N}$. These coincide with regions where the divergent flow aloft associated with enhanced convection in the El Niño region intersects with regions of higher absolute vorticity, so are due to the advection of vorticity (not shown). This anomaly is responsible for the anticyclonic circulation anomaly (solid contours) in the eastern subtropical Pacific which appears to be the start of a broad wave train that influences the North Pacific and North America. Over parts of Central America and the western Caribbean Sea there is a region of 

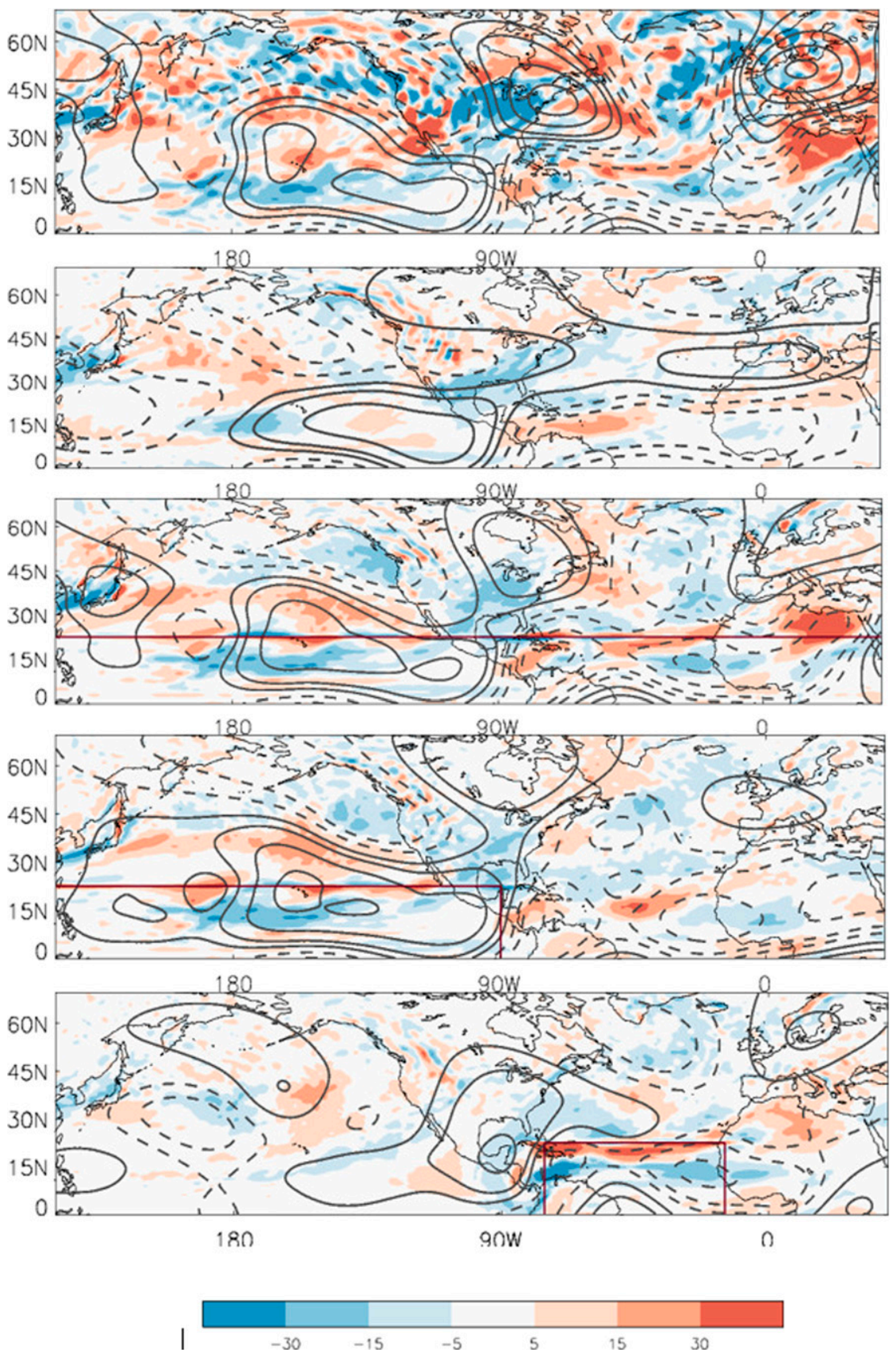

FIG. 4. Rossby wave source analysis in December: mean anomalous Rossby wave source at $200 \mathrm{hPa}$ (shading; $10^{-11} \mathrm{~s}^{-2}$ ) and azonal component of streamfunction at $200 \mathrm{hPa}$ (contours at $\pm 2, \pm 5, \pm 10$, and $\pm 15 \times 10^{6} \mathrm{~m}^{2} \mathrm{~s}^{-1}$, with negative contours dashed) for (top) ERAI, (top middle) Glosea5, (middle) all-tropics relaxation, (bottom middle) tropical Pacific relaxation, and (bottom) tropical Atlantic relaxation.

positive RWS, with a smaller region of negative RWS in the eastern Caribbean. These are due to anomalous upper convergence and divergence, respectively, and induce a cyclonic circulation anomaly (dashed contours) in the upper flow. This feature appears to be at the start of the wave train extending into the extratropical North Atlantic. Further RWS features are present in the subtropical North Atlantic Ocean, which produce a smaller cyclonic anomaly near the coast of Africa.

The RWS for GloSea5 for December is shown in Fig. 4b. The Pacific RWS pattern is broadly similar to 
that derived from reanalysis. In the Atlantic, the positive anomaly over Central America is present, but much weaker, and the small negative anomaly in the Eastern Caribbean in reanalysis is replaced by a larger anomaly of the opposite sign. This extends into the mid-Atlantic, but the eastern Atlantic RWS dipole was not predicted in the GloSea5 ensemble mean. Thus while the observed cyclonic anomaly is established in the subtropical Atlantic, it is very broad and does not possess the centers of action that are evident in reanalysis. Perhaps unsurprisingly, the extratropical circulation anomalies in the North Atlantic region show a similarly broad, zonal structure. In particular, the lack of the necessary RWS features in the Central America-Caribbean region appears to be the reason why the wave train that is seen in reanalysis was not forecast.

Further support for the importance of the Caribbean region comes from the relaxation experiments. By construction, the all-tropics experiment closely reproduces the tropical RWS sources and streamfunction anomalies seen in reanalysis, including the cyclonic anomaly in this region. As shown above, this experiment shows extratropical wave patterns in the North Atlantic that are very similar, albeit weaker, to those seen in reanalysis. In contrast, the tropical Pacific experiment has relatively small circulation anomalies in the North Atlantic (see above). There is a feature resembling the observed Caribbean cyclonic anomaly, but it is considerably weaker and is shifted southward over the coast of South America. The RWS pattern in the tropical Atlantic is actually similar to that in the reanalysis, suggesting both that the tropical Atlantic was being strongly influenced by the tropical Pacific in December 2015 and that the model we use can reproduce this connection, at least in part. The reason that only weak tropical streamfunction anomalies are produced appears to be that the RWS anomalies are somewhat weaker than observed. In the tropical Atlantic experiment, the observed RWS pattern is essentially reproduced, although there are some differences, such as the excessively strong RWS dipole over the eastern Caribbean. It is possible that this arises through some level of dynamical inconsistency near the edge of the relaxation domain. Nevertheless, the dipole between Central America and the Caribbean is present to some extent (even though this lies partly outside the relaxation region). This gives rise to a cyclonic anomaly over the Caribbean. There also appears to be a North Atlantic wave train in this experiment, suggesting once more that the Caribbean feature is key to its generation.

In the late winter, the ERAI streamfunction anomalies for February (Fig. 5a) show the continuing El Niño-related pattern over the Pacific, and a wavelike pattern stretching from the tropical to the midlatitude North Atlantic. The RWS field in the subtropical Atlantic shows a northwest to southeast dipole associated with upperlevel convergence and divergence respectively. These features give rise to the cyclonic anomaly in the subtropics, and thereby appear to be the cause of the wave train in the North Atlantic, leading to the ridging pattern in the central North Atlantic seen in the MSLP pattern, and the low MSLP anomaly over Scandinavia. GloSea5 (Fig. 5b) reproduces these patterns, although the amplitude of the tropical RWS anomalies are weaker. Unsurprisingly, the relatively weak RWS anomalies in the forecast appear in turn to trigger predicted streamfunction anomalies which are weaker than those in reanalysis.

The all-tropics relaxation experiment successfully reproduces most of the extratropical features seen in the reanalysis. In the North Atlantic, midlatitude responses in the azonal streamfunction (Fig. 5c) are reproduced, but are weaker than observed, despite the tropical cyclonic anomaly being close to its observed strength through the construction of the experiment. The tropical Pacific relaxation experiment (Fig. 5d) reproduces RWS and streamfunction patterns in the North Pacific, but bears limited resemblance to the reanalysis pattern in the North Atlantic. Nevertheless, forcing from the Pacific does give a subtropical RWS dipole in the tropical Atlantic (approximately $10^{\circ}-15^{\circ} \mathrm{N}$ ). This is weaker and displaced southeastward, however, relative to reanalysis. As a result, the associated circulation anomaly is also weaker and shifted and does not appear to be capable of producing a noticeable wave train into midlatitudes.

The tropical Atlantic relaxation experiment (Fig. 5e) has the observed RWS and streamfunction patterns in the tropical Atlantic by construction. Despite this, anomalies corresponding to the subsequent nodes of the observed North Atlantic wave train are, while present to some extent, very weak. It is noticeable that the region of negative RWS seen to the north of the relaxation domain in the reanalysis is exaggerated near the domain's northern edge. This may be in part an artifact of relaxation, and could be responsible for disrupting the wave patterns. Nevertheless, the fact that even a limited wave train is generated adds to the impression that the observed midlatitude response was modulated by anomalies in the tropical Atlantic Ocean.

In summary, circulation patterns in February were well forecast by GloSea5 even if the extratropical signals were weaker than actually occurred. The relaxation experiments point to tropical Atlantic anomalies as the source of these signals. Those anomalies themselves are at least partly a result of the strong El Niño in the 

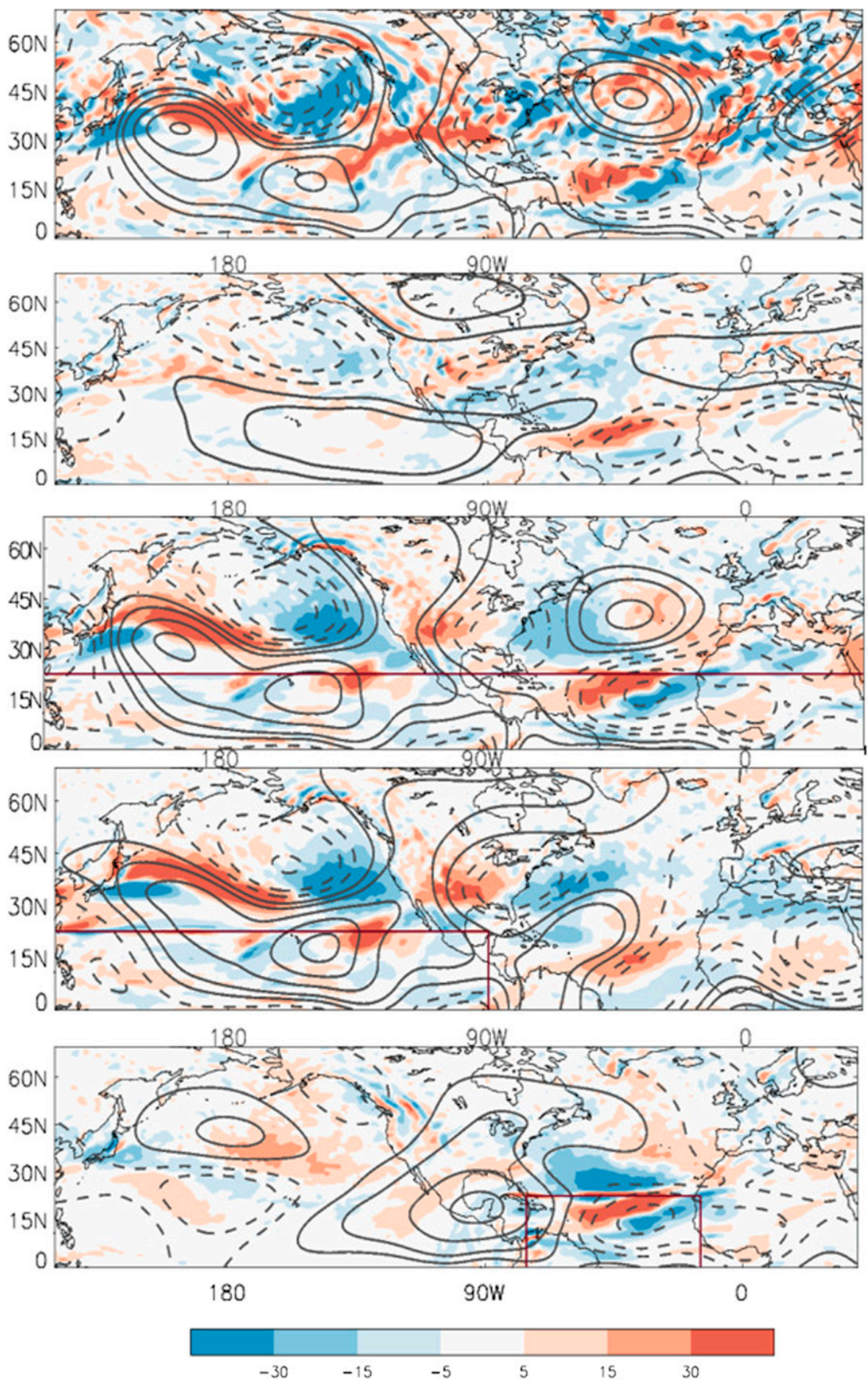

FIG. 5. As in Fig. 4, but for February.

tropical Pacific and its resulting effect on the Walker circulation.

\section{Discussion and conclusions}

In this paper, we have aimed to identify the drivers of the weather patterns of winter 2015/16, assess the performance of the GloSea5 seasonal forecasting system in predicting these patterns, and isolate specific areas where the forecasting system could usefully be improved. In December 2015 record rainfall occurred over the United Kingdom, in part due to strong and persistent southwesterly flow, and later in winter 2015/16 there was a shift to relatively colder, drier 
conditions. Overall this was consistent with the effects of the strong El Niño in the tropical Pacific Ocean. These teleconnections are represented in HadGEM3, so in November 2015 the Met Office GloSea5 seasonal prediction system gave a good indication of an increased likelihood of the wet and stormy conditions in December and predicted the response to a strong El Niño in February. In December, however, some of the specific details of the observed circulation pattern, such as the mid-Atlantic trough feature that ensured a southwesterly rather than a westerly mean flow, were not captured by the prediction system. Had this additional component been confidently predicted by GloSea5, it would have provided an even greater indication of the risk of extreme rainfall.

Comparing the key dynamical features of the reanalysis with those in corresponding forecasts shows that Rossby wave activity visible in the reanalysis 200hPa streamfunction in the North Atlantic sector was very much weaker or absent in the forecast ensemble mean. Specifically, a dipole in the Rossby wave source field in the Caribbean seen in reanalysis which was replaced by a single Rossby wave source which was both weaker and shifted eastward in the forecast ensemble mean.

The next stage of identifying and isolating the causes of the extratropical response in winter 2015/16 was to look at the role of the tropics, both as a whole and by individual ocean basin. We used seasonal-length experiments with a coupled ocean-atmosphere climate model in which model fields were relaxed to reanalysis winds and temperatures in specified domains. This effectively imposed a "perfect forecast" over the relaxed regions, with a view to seeing what the extratropical response would be if this could be realized. The results were then used to trace which parts of the tropics wave responses originated from, and also to identify which aspects of tropical predictability could benefit from system improvements (while recognizing that some aspects of observed wintertime circulation might be intrinsically unpredictable). We relaxed the whole of the tropics, the tropical Atlantic and the tropical Pacific. We did not carry out a specific experiment for the Indian Ocean as the results appear to show that the atmospheric patterns in the North Atlantic and North Pacific are primarily explained by tropical conditions within their own basin. Nevertheless, the Indian Ocean may have had a contributory effect that we have not assessed and might potentially be of more importance in other years.

When the tropical atmosphere as a whole was relaxed to reanalysis, we obtained a very good simulation of the MSLP and upper-tropospheric circulation anomalies in the extratropics, both in early and late winter. In particular, the all-tropics relaxation experiment was able to reproduce the southwesterly flow over the United Kingdom in December. This highlights the role of the tropical atmosphere in constraining the extratropics in winter $2015 / 16$, a similar result to that found for other winters (Greatbatch et al. 2015; Watson et al. 2016; Knight et al. 2017).

Despite the far-reaching effects of the large El Niño event in winter 2015/16, the tropical Pacific relaxation experiment did not reproduce the observed midlatitude circulation anomalies over the North Atlantic in either December or February. In fact, in February, the simulations showed a negative NAO response to El Niño, which is characteristic of the response to moderate $\mathrm{El}$ Niño (Toniazzo and Scaife 2006). Only when the tropical Atlantic was relaxed were MSLP and uppertropospheric circulation patterns similar to those in reanalysis simulated. This demonstrates the importance of this region in producing features of the winter in the North Atlantic, including the southward excursion of the mid-Atlantic flow which increased rainfall in December and the shift to a pattern that brought a cooler and drier northwesterly flow in February. Note that where the relaxation experiments reproduced the observed patterns of the extratropical circulation anomalies, the anomalies were smaller than in the reanalysis. This feature is shared by the predictions from GloSea5 and is an outstanding problem in midlatitude seasonal prediction (Eade et al. 2014).

The contrasting behavior in response to Pacific and Atlantic relaxation is consistent with the mechanisms proposed by Toniazzo and Scaife (2006), and in particular with the differing responses to moderate and strong El Niño events. A negative NAO response in late winter follows a moderate El Niño event (Ineson and Scaife; 2009), occurring as a result of the increased planetary wave amplitudes associated with the deepening of the Aleutian low. This allows stronger planetary wave amplitudes and more wave breaking at the level of the stratospheric polar night jet, increasing the likelihood of sudden stratospheric warmings. It has been shown that SSWs create downward-propagating signals that lead, on average, to negative NAO (Baldwin and Dunkerton 1999; Scaife et al. 2008). However, in strong El Niño events, Toniazzo and Scaife (2006) showed that this stratospheric mechanism is counteracted by a direct tropospheric response initiated in the Atlantic sector by an extension of the downward branch of the Walker circulation. This lies outside the tropical Pacific relaxation region, so is not constrained to happen in the tropical Pacific relaxation experiment. Nevertheless, the model might be expected to be able to generate these 
remote dynamical responses. This does not appear to be the case, however, with the North Atlantic atmospheric circulation response being similar to the canonical El Niño response. Note, however, that because the hindcast set spans all of the initial conditions from 1996 to 2009, the initialization of near-surface temperatures in the tropical Atlantic Ocean in this experiment will not be those concomitant with a large, mature El Niño event, so we would not necessarily expect the coupled response to be correct.

Dynamical analysis using the RWS diagnostic for December shows that upper-level anomalies over Central America and the Caribbean are responsible for generating a Rossby wave train extends into the midlatitude North Atlantic. The cyclonic node of this pattern lying over the central northern North Atlantic Ocean amplifies the meridionality of the flow compared to the GloSea5 prediction, which is essentially zonal. While the GloSea5 ensemble mean does show some evidence of these tropical RWS anomalies, their amplitudes, and those of the upper-tropospheric circulation anomalies they induce, are too small. As a result, any wave train produced is too weak to be seen in the prediction of the extratropics. The relaxation experiments show that a vestige of the Caribbean source is present in the tropical Pacific experiment (the Caribbean lying outside the relaxation domain). This suggests that there is a teleconnection between these regions, but it is not clear whether this implies that the Atlantic wave train is wholly forced from the tropical Pacific indirectly via the tropical Atlantic or whether there is also a component of forcing intrinsic to the tropical Atlantic. The former case would imply a deficiency in the model.

For February, the dynamical analysis links wave sources in the central subtropical Atlantic with a different wave pattern to that seen in December, which produces different weather for the United Kingdom. Again, GloSea5 produces a weak version of these sources, and hence a weak (but identifiable) wave train. The analysis for February shows further evidence for an influence from the Pacific as the tropical Pacific relaxation experiment produces a version of the Atlantic RWS anomalies, albeit weaker than observed and southward shifted.

The key RWS features at the edge of the tropics are likely to be linked to convective anomalies deeper in the tropics where convective activity within the ITCZ is much more pronounced, although we do not analyze their causes in detail here. Previous work (Knight et al. 2017) showed a link between convective anomalies over the western Amazon basin and RWS anomalies over the Caribbean via a modulation of the local Hadley circulation in the Northern Hemisphere winter of 2013/14, and in the winter of $2015 / 16$, features of the monthly mean rainfall predicted by GloSea5 and in an observationally based rainfall dataset were also of relevance. There are clearly differences as well as significant similarities between the forecast and observations. We note that the December rainfall on the equator just west of South America is much less in GloSea5 than is indicated by the observational dataset. We might speculate that the proximity of this discrepancy to the key Central American region identified in our analysis makes it a candidate for producing differences in the divergent outflow from that region and hence RWS anomalies further north. There may be other possibilities, however, as links between tropical rainfall anomalies and the Atlantic RWS pattern in February are not obvious.

In this work we have shown that tropical forcing, in particular from the Atlantic sector, was important for generating the sequence of weather patterns in the United Kingdom in the winter of 2015/16, including the extreme rainfall in December 2015. The utility of this is that by localizing the key remote influences involved we can focus on the regions where prediction systems could be improved to deliver better forecasts of potential future extreme winter events in the United Kingdom and beyond.

Acknowledgments. This work was supported by the Joint UK BEIS/Defra Met Office Hadley Centre Climate Programme (GA01101). We thank Craig MacLachlan for his help in setting up the suites of numerical model experiments used in this study. We also thank the three anonymous referees whose comments have helped to refine this paper.

\section{REFERENCES}

Ayarzagüena, B., S. Ineson, N. J. Dunstone, M. P. Baldwin, and A. A. Scaife, 2018: Intraseasonal effects of El Niño-Southern Oscillation on North Atlantic Climate. J. Climate, 31, 88618873, https://doi.org/10.1175/JCLI-D-18-0097.1.

Baldwin, M. P., and T. J. Dunkerton, 1999: Propagation of the Arctic Oscillation from the stratosphere to the troposphere. J. Geophys. Res., 104, 30 937-30 946, https://doi.org/10.1029/ 1999JD900445.

weather regimes. Science, 294, 581-584, https://doi.org/ 10.1126/science.1063315.

Best, M. J., and Coauthors, 2011: The Joint UK Land Environment Simulator (JULES), model description-Part 1: Energy and water fluxes. Geosci. Model Dev., 4, 677-699, https://doi.org/ 10.5194/gmd-4-677-2011.

Birner, T., and J. R. Albers, 2017: Sudden stratospheric warmings and anomalous upward wave activity flux. SOLA, 13A, 8-12, https://doi.org/10.2151/sola.13A-002.

Boer, G. J., and K. Hamilton, 2008: QBO influence on extratropical predictive skill. Climate Dyn., 31, 987-1000, https://doi.org/ 10.1007/s00382-008-0379-5. 
Brönnimann, S., 2007: Impact of El Niño-Southern Oscillation on European climate. Rev. Geophys., 45, RG3003, https://doi.org/ 10.1029/2006RG000199.

—- E. Xoplaki, C. Casty, A. Pauling, and J. Luterbacher, 2007: ENSO influence on Europe during the last centuries. Climate Dyn., 28, 181-197, https://doi.org/10.1007/s00382-006-0175-z.

Brown, A., S. Milton, M. Cullen, B. Golding, J. Mitchell, and A. Shelly, 2012: Unified modeling and prediction of weather and climate: A 25-year journey. Bull. Amer. Meteor. Soc., 93, 1865-1877, https://doi.org/10.1175/BAMS-D-12-00018.1.

Christidis, N., and P. Stott, 2015: Extreme rainfall in the United Kingdom during winter 2013/14: The role of atmospheric circulation and climate change [in "Explaining Extreme Events of 2014 from a Climate Perspective"]. Bull. Amer. Meteor. Soc., 96 (12), S46-S50, https://doi.org/10.1175/BAMS-D-1500094.1.

Coumou, D., and S. Rahmstorf, 2012: A decade of weather extremes. Nat. Climate Change, 2, 491-496, https://doi.org/ 10.1038/nclimate1452.

Dee, D. P., and Coauthors, 2011: The ERA-Interim reanalysis: Configuration and performance of the data assimilation system. Quart. J. Roy. Meteor. Soc., 137, 553-597, https://doi.org/ 10.1002/qi.828.

Eade, R., D. Smith, A. Scaife, E. Wallace, N. Dunstone, L. Hermanson, and N. Robinson, 2014: Do seasonal-todecadal climate predictions underestimate the predictability of the real world? Geophys. Res. Lett., 41, 5620-5628, https:// doi.org/10.1002/2014GL061146.

Fereday, D. R., J. R. Knight, A. A. Scaife, and C. K. Folland, 2008: Cluster analysis of North Atlantic-European circulation types and links with tropical Pacific sea surface temperatures. J. Climate, 21, 3687-3703, https://doi.org/10.1175/ 2007JCLI1875.1.

- A. Maidens, A. Arribas, A. A. Scaife, and J. R. Knight, 2012: Seasonal forecasts of northern hemisphere winter 2009/10. Environ. Res. Lett., 7, 034031, https://doi.org/10.1088/17489326/7/3/034031.

Gollan, G., R. J. Greatbatch, and T. Jung, 2015: Origin of variability in Northern Hemisphere winter blocking on interannual to decadal timescales. Geophys. Res. Lett., 42, 10 037-10 046, https://doi.org/10.1002/2015GL066572.

Greatbatch, R. J., G. Gollan, T. Jung, and T. Kunz, 2012: Factors influencing Northern Hemisphere winter mean atmospheric circulation anomalies during the period $1960 / 61$ to $2001 / 02$. Quart. J. Roy. Meteor. Soc., 138, 1970-1982, https://doi.org/ 10.1002/qj.1947.

,,--- and -2015 : Tropical origin of the severe European winter of 1962/1963. Quart. J. Roy. Meteor. Soc., 141, 153-165, https://doi.org/10.1002/qj.2346.

Hewitt, H. T., D. Copsey, I. D. Culverwell, C. M. Harris, R. S. R. Hill, A. B. Keen, A. J. McLaren, and E. C. Hunke, 2011: 2011: Design and implementation of the infrastructure of HadGEM3: The next-generation Met Office climate modelling system. Geosci. Model Dev., 4, 223-253, https://doi.org/10.5194/gmd-4223-2011.

Hoerling, M. P., J. W. Hurrell, and T. Xu, 2001: Tropical origins for recent North Atlantic climate change. Science, 292, 90-92, https://doi.org/10.1126/science.1058582.

Horel, J. D., and J. M. Wallace, 1981: Planetary-scale atmospheric phenomena associated with the Southern Oscillation. Mon. Wea. Rev., 109, 813-829, https://doi.org/10.1175/1520-0493(1981) 109<0813:PSAPAW $>2.0$. CO;2.
Huang, J., K. Higuchi, and A. Shabbar, 1998: The relationship between the North Atlantic Oscillation and El Niño-Southern Oscillation. Geophys. Res. Lett., 25, 2707-2710, https://doi.org/ 10.1029/98GL01936.

Hunke, E. C., and W. H. Lipscomb, 2010: CICE: The Los Alamos Sea Ice Model documentation and software user's manual, version 4.1. Doc. LA-CC-06-012, 76 pp., http://csdms.colorado.edu/ w/images/CICE_documentation_and_software_user's_manual.pdf.

Hurrell, J. W., 1995: Decadal trends in the North Atlantic Oscillation: Regional temperatures and precipitation. Science, 269, 676-679, https://doi.org/10.1126/science.269.5224.676.

Ineson, S., and A. A. Scaife, 2009: The role of the stratosphere in the European climate response to El Niño. Nat. Geosci., 2, 32 36, https://doi.org/10.1038/ngeo381.

Jong, B.-T., M. Ting, R. Seager, N. Henderson, and D. E. Lee, 2018: Role of equatorial Pacific SST forecast error in the late winter California precipitation forecast for the 2015/16 El Niño. J. Climate, 31, 839-852, https://doi.org/10.1175/JCLI-D-170145.1.

Kendon, M., and M. McCarthy, 2015: The UK's wet and stormy winter of 2013/2014. Weather, 70, 40-47, https://doi.org/ $10.1002 /$ wea. 2465 .

,,-- S. Jevrejeva, and T. Legg, 2016: State of the UK Climate 2015. Met Office Rep., 66 pp., https://www.metoffice.gov.uk/ binaries/content/assets/mohippo/pdf/climate/state_of_the_ uk_climate_2015.pdf.

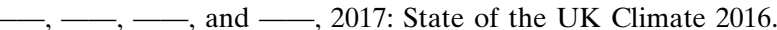
Met Office Rep., 60 pp., https://www.metoffice.gov.uk/ binaries/content/assets/mohippo/pdf/uk-climate/state-of-theuk-climate/mo-state-of-uk-climate-2016-v4.pdf.

Knight, J. R., and Coauthors, 2017: Global meteorological influences on the record UK rainfall of winter 2013-14. Environ Res. Lett., 12, 074001, https://doi.org/10.1088/1748-9326/aa693c.

Lavers, D. A., R. P. Allan, E. F. Wood, G. Villarini, D. J. Brayshaw, and A. J. Wade, 2011: Winter floods in Britain are connected to atmospheric rivers. Geophys. Res. Lett., 38, L23803, https:// doi.org/10.1029/2011GL049783.

Luo, D., 2007: Dynamics of eddy-driven low-frequency dipole modes. Part I: A simple model of North Atlantic Oscillations. J. Atmos. Sci., 64, 3-28, https://doi.org/10.1175/JAS3818.1.

MacLachlan, C., and Coauthors, 2015: Global seasonal forecast system version 5 (GloSea5): A high-resolution seasonal forecast system. Quart. J. Roy. Meteor. Soc., 141, 1072-1084, https://doi.org/10.1002/qj.2396

Madec, G., 2016: NEMO ocean engine. Note du Pôle de modélisation de l'Institut Pierre-Simon Laplace 27, 386 pp., https:// www.nemo-ocean.eu/wp-content/uploads/NEMO_book.pdf.

Marshall, A. G., and A. A. Scaife, 2009: Impact of the QBO on surface winter climate. J. Geophys. Res., 114, D18110, https:// doi.org/10.1029/2009JD011737.

Mogensen, K., M. A. Balmaseda, and A. T. Weaver, 2012: The NEMOVAR ocean data assimilation system as implemented in the ECMWF ocean analysis for System 4. ECMWF Tech. Memo 668, 61 pp., https://doi.org/10.21957/x5y9yrtm.

Pall, P., T. Aina, D. A. Stone, P. A. Stott, T. Nozawa, A. G. J. Hilberts, D. Lohmann, and M. R. Allen, 2011: Anthropogenic greenhouse gas contribution to flood risk in England and Wales in autumn 2000. Nature, 470, 382-385, https://doi.org/ 10.1038/nature09762.

Parry, S., L. Barker, I. Prosdocimi, M. Lewis, J. Hannaford, and S. Clemas, 2016: Hydrological summary for the United Kingdom: December 2015. NERC/Centre for Ecology and Hydrology Rep., 12 pp., http://nora.nerc.ac.uk/id/eprint/512654. 
Pendergrass, A., and Coauthors, 2016: The Climate Data Guide: GPCP (Monthly): Global Precipitation Climatology Project. NCAR, accessed 3 March 2017, https://climatedataguide.ucar.edu/climate-data/ gpcp-monthly-global-precipitation-climatology-project.

Rayner, N. A., D. E. Parker, E. B. Horton, C. K. Folland, L. V. Alexander, D. P. Rowell, E. C. Kent, and A. Kaplan, 2003: Global analyses of sea surface temperature, sea ice, and night marine air temperature since the late nineteenth century. J. Geophys. Res., 108, 4407, https://doi.org/10.1029/ 2002JD002670.

Sardeshmukh, P. D., and B. J. Hoskins, 1988: The generation of global rotational flow by steady idealized tropical divergence. J. Atmos. Sci., 45, 1228-1251, https://doi.org/10.1175/15200469(1988)045<1228:TGOGRF $>2.0$. CO;2.

Scaife, A. A., C. K. Folland, L. V. Alexander, A. Moberg, and J. R. Knight, 2008: European climate extremes and the North Atlantic Oscillation. J. Climate, 21, 72-83, https://doi.org/ 10.1175/2007JCLI1631.1.

__ , and Coauthors, 2014a: Skillful long-range prediction of European and North American winters. Geophys. Res. Lett., 41 , 2514-2519, https://doi.org/10.1002/2014GL059637.

— oscillation and its northern winter teleconnection on seasonal to decadal timescales. Geophys. Res. Lett., 41, 1752-1758, https://doi.org/10.1002/2013GL059160.

— , and Coauthors, 2017a: Predictability of European winter 2015/2016. Atmos. Sci. Lett., 18, 38-44, https://doi.org/10.1002/ asl.721.

_ regional winter climate predictions. Quart. J. Roy. Meteor. Soc., 143, 1-11, https://doi.org/10.1002/qj.2910.

Shimizu, M. H., and I. F. de Albuquerque Cavalcanti, 2011: Variability patterns of Rossby wave patterns. Climate Dyn., 37, 441-454, https://doi.org/10.1007/s00382-010-0841-z.
Smith, D. M., A. A. Scaife, R. Eade, and J. R. Knight, 2014: Seasonal to decadal prediction of the winter North Atlantic Oscillation: Emerging capability and future prospects. Quart. J. Roy. Meteor. Soc., 142, 611-617, https://doi.org/10.1002/ qj. 2479.

Stan, C., D. M. Straus, J. S. Frederiksen, H. Lin, E. D. Maloney, and C. Schumacher, 2017: Review of tropical-extratropical teleconnections on intraseasonal time scales. Rev. Geophys., 55 , 902-937, https://doi.org/10.1002/2016RG000538.

Thompson, D. W. J., S. Lee, and M. P. Baldwin, 2003: Atmospheric processes governing the Northern Hemisphere Annular Mode/North Atlantic Oscillation. The North Atlantic Oscillation: Climatic Significance and Environmental Impact, Geophys. Monogr., Vol. 134, Amer. Geophys. Union, 81-112.

Toniazzo, T., and A. A. Scaife, 2006: The influence of ENSO on winter North Atlantic climate. Geophys. Res. Lett., 33, L24704, https://doi.org/10.1029/2006GL027881.

Ummenhofer, C. C., H. Seo, Y.-O. Kwon, R. Parfitt, S. Brands, and T. M. Joyce, 2017: Emerging European winter precipitation pattern linked to atmospheric circulation changes over the North Atlantic region in recent decades. Geophys. Res. Lett., 44, 8557-8566, https://doi.org/10.1002/2017GL074188.

Walters, D. N., and Coauthors, 2011: The Met Office Unified Model Global Atmosphere 3.0/3.1 and JULES Global Land 3.0/3.1 configurations. Geosci. Model Dev., 4, 919-941, https:// doi.org/10.5194/gmd-4-919-2011.

Watson, P. A. G., A. Weisheimer, J. R. Knight, and T. N. Palmer, 2016: The role of the Tropical West Pacific in the extreme Northern Hemisphere winter of 2013/2014. J. Geophys. Res. Atmos., 121, 1698-1714, https://doi.org/ 10.1002/2015JD024048.

Yeh, S.-W., and Coauthors, 2018: ENSO Atmospheric teleconnections and their response to greenhouse gas forcing. Rev. Geophys., 56, 185-206, https://doi.org/10.1002/ 2017RG000568. 